\title{
Soft Neuro Computing GUI-based Diabetes Mellitus
}

\author{
Agus Rusgiyono $^{1 *}$, Hasbi Yasin $^{1 * *}$, Abdul Hoyyi ${ }^{1}$, Rezzy Eko Caraka ${ }^{2 * * *}$ \\ agus.rusgi@gmail.com ${ }^{1 *}$, hasbiyasin@live.undip.ac.id ${ }^{* *}$, rezzyekocaraka@gmail.com**** \\ Departement of Statistics, Diponegoro University, Semarang, Indonesia ${ }^{1}$ \\ School of Mathematical Sciences, The National University of Malaysia, Bangi, Malaysia ${ }^{2}$
}

\begin{abstract}
Health is a vital aspect of life. According to this, we need to improve public health due to an unhealthy lifestyle which may lead to the occurrence of various kinds of diseases. Diabetes Mellitus (DM) is one negative impacts left by an unhealthy lifestyle which is caused by high blood sugar levels. Numbers of diabetes patients get late treatments due to delayed identification on them. In fact, if a diagnosis report conducted earlier, the treatment can be given earlier as well, and bad conditions may be avoided. Therefore, a system identifying diabetes is needed so that the disease can be detected as fast, accurate, and early as possible. To tackle this issue, we aimed to design soft computing system for early detection of diabetes mellitus by using neural network and binary sigmoid activation function. In a nutshell, The accuracy level of the DM detection was $92.44 \%$.
\end{abstract}

Keywords: Soft Computing; FFNN; Diabetes Mellitus; Classification

\section{Introduction}

Health is a vital aspect of life. Many problems occur in the improvement of public health due to an unhealthy lifestyle, which may lead to the occurrence of various kinds of diseases [1]. Metabolic disease is one of the examples of the negative impacts of an unhealthy lifestyle. The problem frequently occurs in the community is Diabetes Mellitus (DM). DM caused by high blood sugar levels. This becomes a severe challenge for the health care system in this nation [2]. Currently, DM is one of the health problems that affect productivity and reduce the quality of human resources. According to the World Health Organization's records. Indonesia ranked sixth among the countries with most diabetes patients after India, China, Russia, Japan, and Brazil. The number of DM patients in Indonesia keeps increasing. It is known that in 1995 Indonesia had approximately 5 million DM patients with the increase rate is around 230 thousand patients per year. In 2025, the number of Diabetes patients in Indonesia is estimated to reach 12 million people. The increase of this number is caused by the rising number of senior population and change in the lifestyle, from the dietary habit or the types of food consumed by the lack of physical activities. This especially is the case of the adult age group and above across all economical-social status. Besides, the increase of the number of DM cases is also caused by the lack of health, the lack of specific monitoring devices and medicines, especially in remote areas, and the lack of uniformity in DM patients management by front-line doctors.

Numbers of diabetes patients get late treatments, which results in the delayed identification on them. In fact, if the diagnosis is carried out earlier, the treatment can be given earlier as well and harmful conditions may be avoided. In addition to sex and age, the classification of being declared having DM or not is also based on a number of health tests such as the checking on fasting blood sugar level, blood sugar level two hours after meal, HDL (High Density

ICASI 2018, April 23-24, Medan, Indonesia

Copyright (c) 2018 EAI

ISBN: 978-1-63190-162-1 
Lipoprotein) level, LDL (Low Density Lipoprotein) level, triglycerides level, and hbA1c level. Therefore, a system identifying diabetes is needed so that the disease can be detected as fast, accurate, and early as possible. The methods frequently used in this problems is Discriminant Analysis, liniear model [3] and Logistic Regression [4], which require a number of assumptions, especially in relation to data distribution. One of the methods that can deal with this issue is machine learning techniques such as Support vector machine [5], support vector regression [6][7][8], and Artificial Neural Network (ANN) which usually abbreviated as NN[9][10]. NN has the ability of learning and adopting a new situation by memorizing the data pattern in the past[11], even after the occurrence of noise. Therefore, in this research, the classification analysis for early detection of Diabetes Mellitus used FFNN model.

\section{Material and Methods}

\subsection{Neural Network}

Artificial Neural Network (ANN), or more commonly known as Neural Network (NN), is an information processing system which has characteristics similar to the biological neural network. Haykin [12] stated that ANN is a machine designed for modeling the way the human brain works in doing specific functions or tasks. This machine can store knowledge based on experiences and make the store of knowledge come in handy. Kusumadewi [13] described that in processing information, the human brain is equipped with some neurons that do simple tasks. The neurons in the human brain are interconnected, enabling the brain does a complex processing function. The information processing in human is adaptive, meaning that the link between the neurons takes place dynamically, and the brain is continuously capable of learning unfamiliar information. At the same time, Several definitions have been conveyed by Pandjaitan [14] as follows:

1. NN is a computer-based information processing technique that simulates and model's biological neural system.

2. A mathematical model containing a large number of processing elements that are organized in layers.

3. A computing system comprised of some simple, interconnected processing elements to process information through inputs from outside and able to respond to dynamic conditions.

4. $\mathrm{NN}$ is a computing technology based only on the biological neural model and used to simulate neural model behaviors and works toward a wide range of inputs.

The network architecture in neural network (NN) is a structure of neurons in layers, and the connection pattern is deep and inter-layer. The neurons in one particular layer will have the same pattern of connectedness [15]. NN consists of following layers:

1. Input layer which refers to the layer that receives inputs from outside network.

2. Hidden Layer

Which refers to a layer that is located in one or some layers and not connected directly to the conditions outside the network. A hidden layer usually lay between the input layer and an output layer. It is usually in the form of one or some layers in a network.

3. Output layer 
Which referees to the layer that produces outputs from the network. In this research, the researcher used multi-layer network with Feedforward Neural Networks (FFNN) model. FFNN is a specific form of Multi-Layer Perceptron (MLP) with one hidden layer [10] [16]. Figure 1 explain the illustration of FFNN also, the typical form of FFNN model is written in the following equation 1 :

$$
X_{t}=\psi_{o}\left\{w_{b o}+\sum_{j=1}^{H} w_{j o} \psi_{j}\left(w_{b j}+\sum_{i=1}^{p} w_{i j} X_{t-i}\right)\right\}
$$

with

$\psi_{o} \quad$ : acthe tivation function used in output layer

$\psi_{j} \quad$ : activation function used in hidden layer

$w_{i j} \quad:$ the weight of neuron $\mathrm{i}$ in input layer to neuron $\mathrm{j}$ in hidden layer

$w_{b j} \quad:$ the bias weight in input layer to neuron $\mathrm{j}$ in hidden layer

$w_{j o} \quad:$ the weight of neuron $\mathrm{j}$ in hidden layer to output layer

$w_{b o}:$ the bias weight in hidden layer to output layer

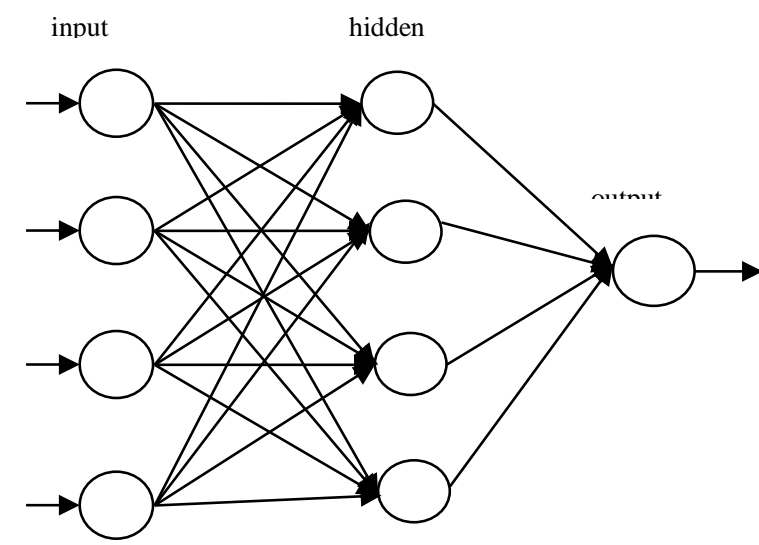

Fig 1. Feedforward Neural Network (FFNN) Illustration

\subsection{Neuro-Model Architecture}

In this paper, we used FFNN model architecture used with the determination of neuron number in a hidden layer based on table 1 .

Table 1. Empirical Formula for Determining the Number of Neurons in Hidden Layer $N_{o}$ (Output neuron) The empirical formula for calculating the number of neurons in the hidden

\begin{tabular}{cc}
$N_{o}$ (Output neuron) & layer \\
\hline 1 & $2 * N_{i}+1$ \\
2 & $3 * N_{i}$ \\
3 & $\frac{2+N_{i} * N_{o}+0.5 N_{i} *\left(N_{o}^{2}+N_{i}\right)-3}{N_{i}+N_{o}}$ \\
4 & $\left(2 * N_{i}\right) / 3$ \\
5 & $\sqrt{N_{o} * N_{i}}$ \\
6 & $2 * N_{i}$ \\
& $N_{i}$ (Input Neuron) \\
\hline
\end{tabular}


We performed medical records of patients in the Health Center of the Ministry of Industry, Jakarta, from July 2014 to September 2014, with the case study of Diabetes Mellitus. The attributes are sex, age, fasting sugar level, sugar level two hours after a meal (two-hour postprandial blood sugar level), triglycerides level, LDL (low-density lipoprotein) level, HDL (high-density lipoprotein) level, and hbA1c level. To simulate we were used 416 data. The following are the criteria of categorization of each research variable [17]:

Table 2. Research variables criteria

\begin{tabular}{cc}
\hline Attributes & Description \\
\hline Fasting blood sugar level $(\mathrm{mg} / \mathrm{dL})$ & $80-109=$ good \\
$110-125=$ moderate \\
$\geq 126=$ poor \\
\hline Two-hour postprandial blood sugar level $(\mathrm{mg} / \mathrm{dL})$ & $80-144=$ good \\
$145-179=$ moderate \\
$\geq 180=$ poor \\
\hline HDL $(\mathrm{mg} / \mathrm{dL})$ & $>45=$ good \\
& $\leq 45=$ poor \\
\hline LDL $(\mathrm{mg} / \mathrm{dL})$ & $<100=$ good \\
& $100-129=$ moderate \\
$\geq 130=$ poor \\
\hline Triglycerides $(\mathrm{mg} / \mathrm{dL})$ & $<150=$ good \\
& $150-199=$ moderate \\
$\geq 200=$ poor \\
\hline hbA1c & $<6,5=$ good \\
& $6,5-8=$ moderate \\
& $>8=$ poor \\
\hline
\end{tabular}

The steps for classifying the patients with diabetes using FFNN model in this research consists::

1. Initialize all weights in the hidden layer and output layer

2. Calculate the outputs gained from the neurons in the hidden layer with the binary sigmoid activation function

3. Calculate the outputs gained from the neurons in the binary sigmoid output layer

4. Calculate the error gradient for the neurons in the output layer

5. Calculate the weight correction for the output layer

6. Update all weights in the output layer

7. Calculate the error gradient for the neurons in the hidden layer

8. Calculate the weight correction for the hidden layer

9. Update all weights in the hidden layer

10. Calculate the FFNN classification accuracy value

11. Predict with the best model

\section{Analysis}

Based on the information stating that the research variables are comprised of 8 independent variables, the model formed was FFNN with eight units of neurons in the input layer, 17 units of neuron in the hidden layer and 1 unit of neuron in the output layer. Meanwhile, the activation function used in the hidden layer and output layer was binary sigmoid (sigmoid logistic). Based on the architecture of FFNN network which had already been formed, the total weights or 
parameters to be estimated were 171 weights consisting of $(8 \times 17)$ neuron weights to give input signal in the input layer $\left(w_{i n}\right), 17$ bias weights for the hidden layer $\left(w_{b n}\right), 17$ weights for producing later output $\left(v_{n o}\right)$ and 1 bias weight for output layer $\left(v_{b o}\right)$.

The first step was determining the optimum weight chosen based on the smallest error level. The best FFNN model for the Diabetes Mellitus contracting classification modeling was by using the optimum weight presented in Table 3 and 4 . Based on that model, it was found that the level of classification model error built based on the research data was $7.56 \%$. In other words, the model gained had the accuracy level of $92.44 \%$. Afterward, the optimum weight parameter was used to predict the contracting of Diabetes Mellitus as an attempt of early detection. After the optimum weight was obtained, the next step was building GUI application for detecting whether someone had an indication of contracting Diabetes Mellitus or not. The data input used were the data of medical records of every respondent/patient. The GUI display gained based on the variable used was as shown in Figure 2.

To give an example, if a 50-year-old male patient had fasting blood sugar level of 100 $\mathrm{mg} / \mathrm{dL}$, two-hour postprandial blood sugar level of $135 \mathrm{mg} / \mathrm{dL}$, LDL level of $90 \mathrm{mg} / \mathrm{dL}$, HDL level of $35 \mathrm{mg} / \mathrm{dL}$, Triglycerides level of $165 \mathrm{mg} / \mathrm{dL}$, and hbA1c level of 6 , by clicking the "Check Status" button, he would get information telling him that he was not indicated as contracting Diabetes Mellitus as shown in Figure 3.

Another example is when a 52-year-old male patient had fasting blood sugar level of $130 \mathrm{mg} / \mathrm{dL}$, two-hour postprandial blood sugar level of $185 \mathrm{mg} / \mathrm{dL}$, LDL level of $125 \mathrm{mg} / \mathrm{dL}$, HDL level of $50 \mathrm{mg} / \mathrm{dL}$, Triglycerides level of $170 \mathrm{mg} / \mathrm{dL}$, and hbA1c level of 9, by clicking the "Check Status" button he would get information telling him that he was indicated as positively contracting Diabetes Mellitus as shown in Figure 4.

Table 3. Final Weight from the Input Layer to Hidden Layer

\begin{tabular}{rrrrrrrrrr}
\hline & \multicolumn{1}{c}{$\mathbf{X}_{\mathbf{1}}$} & \multicolumn{1}{c}{$\mathbf{X}_{\mathbf{2}}$} & \multicolumn{1}{c}{$\mathbf{X}_{\mathbf{3}}$} & \multicolumn{1}{c}{$\mathbf{X}_{\mathbf{4}}$} & \multicolumn{1}{c}{$\mathbf{X}_{\mathbf{5}}$} & \multicolumn{1}{c}{$\mathbf{X}_{\mathbf{6}}$} & \multicolumn{1}{c}{$\mathbf{X}_{\mathbf{7}}$} & \multicolumn{1}{c}{$\mathbf{X}_{\mathbf{8}}$} & \multicolumn{1}{c}{ bias } \\
\hline $\mathbf{Z}_{\mathbf{1}}$ & -2.4313 & -0.9977 & 3.4510 & -0.8074 & -1.4687 & -4.0260 & -0.4526 & -0.4246 & -0.6832 \\
$\mathbf{Z}_{\mathbf{2}}$ & -9.6465 & -0.5677 & 0.4241 & -0.1713 & 1.9478 & 0.8317 & -3.6958 & 2.7202 & -2.2210 \\
$\mathbf{Z}_{\mathbf{3}}$ & 0.2950 & 4.7276 & -5.9636 & -6.5189 & -4.6692 & 3.9081 & 3.6545 & -4.7685 & 5.0188 \\
$\mathbf{Z}_{\mathbf{4}}$ & 4.7930 & -6.0173 & -2.4447 & 0.3369 & -3.4850 & 1.6674 & -2.4505 & 4.5892 & 6.6765 \\
$\mathbf{Z}_{\mathbf{5}}$ & 0.0679 & -0.5494 & -0.8014 & -0.9865 & 5.6039 & 0.8486 & 1.2265 & 6.4912 & 0.9233 \\
$\mathbf{Z}_{\mathbf{6}}$ & 3.5456 & 2.8426 & -1.9566 & -3.5035 & -5.2206 & 3.9005 & -3.1040 & -2.0293 & -0.4643 \\
$\mathbf{Z}_{\mathbf{7}}$ & 2.2928 & 12.2727 & 0.4651 & 3.5743 & -0.7969 & -2.5077 & 2.3393 & 5.9101 & -3.2446 \\
$\mathbf{Z}_{\mathbf{8}}$ & -0.4075 & 3.5390 & 3.3678 & 1.5744 & -4.6372 & 0.1863 & 7.6188 & 3.3805 & -0.8318 \\
$\mathbf{Z}_{\mathbf{9}}$ & -4.3261 & -0.5407 & 2.5789 & -1.3273 & 2.3531 & 0.0655 & 1.6566 & 1.1109 & -5.1141 \\
$\mathbf{Z}_{\mathbf{1 0}}$ & 1.5795 & -1.1972 & -1.6519 & -0.4526 & 1.1893 & -2.6246 & 3.2489 & 2.0544 & 5.5490 \\
$\mathbf{Z}_{\mathbf{1 1}}$ & -4.0317 & 2.5773 & -1.3158 & 1.3708 & -0.7212 & -0.7225 & -1.3945 & 0.7620 & 3.5670 \\
$\mathbf{Z}_{\mathbf{1 2}}$ & 1.0873 & -0.4835 & 0.6191 & -0.1256 & -0.9200 & -1.6017 & -8.0706 & -0.9208 & -4.4353 \\
$\mathbf{Z}_{\mathbf{1 3}}$ & -2.8723 & -5.3995 & -1.8675 & -2.3629 & -2.3452 & 7.9226 & -4.1759 & 0.9107 & -10.4819 \\
$\mathbf{Z}_{\mathbf{1 4}}$ & -1.2428 & 0.7851 & 0.8496 & 5.4232 & 0.2276 & -0.7540 & 3.3143 & 3.4732 & 2.6478 \\
$\mathbf{Z}_{\mathbf{1 5}}$ & 1.4043 & 3.3010 & 4.3665 & 3.1970 & -9.0573 & 2.2223 & 3.3252 & 6.5098 & -3.2777 \\
$\mathbf{Z}_{\mathbf{1 6}}$ & -0.2260 & -6.6648 & -5.4049 & -5.7019 & 1.5561 & 3.6339 & -2.7040 & 5.2335 & 5.2739 \\
$\mathbf{Z}_{\mathbf{1 7}}$ & 0.5647 & -0.9011 & 5.7034 & 4.2606 & 3.1530 & -1.4532 & 0.9128 & 2.9981 & -4.5198 \\
\hline
\end{tabular}

Table 4. Final Weight from the Hidden Layer to Output Layer

\begin{tabular}{cccccccccc}
\hline & $\mathbf{Z}_{\mathbf{1}}$ & $\mathbf{Z}_{\mathbf{2}}$ & $\mathbf{Z}_{\mathbf{3}}$ & $\mathbf{Z}_{\mathbf{4}}$ & $\mathbf{Z}_{\mathbf{5}}$ & $\mathbf{Z}_{\mathbf{6}}$ & $\mathbf{Z}_{\mathbf{7}}$ & $\mathbf{Z}_{\mathbf{8}}$ & $\mathbf{Z}_{\mathbf{9}}$ \\
\hline $\mathbf{Y}$ & 8.6719 & 3.3306 & 7.2577 & -2.5167 & 0.0152 & -5.0171 & 4.1498 & -3.5001 & -4.5840 \\
\hline & $\mathbf{Z}_{\mathbf{1 0}}$ & $\mathbf{Z}_{\mathbf{1 1}}$ & $\mathbf{Z}_{\mathbf{1 2}}$ & $\mathbf{Z}_{\mathbf{1 3}}$ & $\mathbf{Z}_{\mathbf{1 4}}$ & $\mathbf{Z}_{\mathbf{1 5}}$ & $\mathbf{Z}_{\mathbf{1 6}}$ & $\mathbf{Z}_{\mathbf{1 7}}$ & bias \\
\hline $\mathbf{Y}$ & -0.8563 & -7.8109 & -3.9522 & 2.8040 & 17.5085 & 4.5316 & -3.9989 & -1.4556 & 0.2032 \\
\hline
\end{tabular}




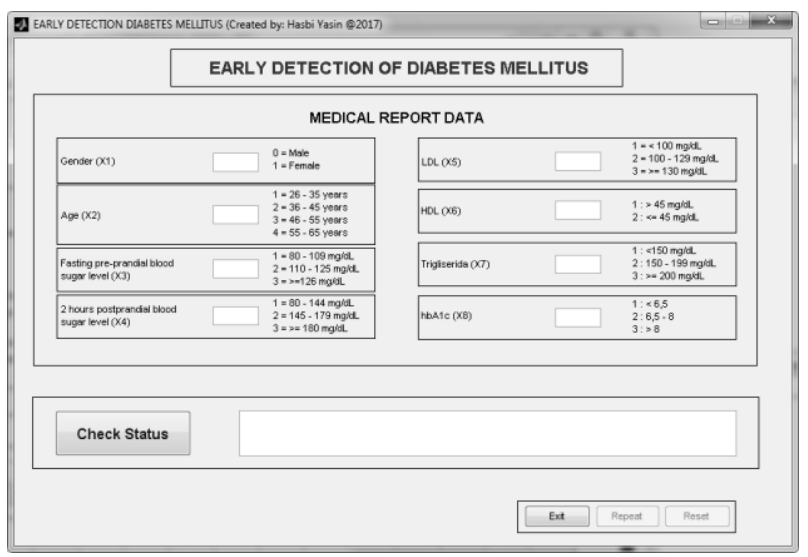

Fig 2. GUI display for Diabetes Mellitus Early Detection Application

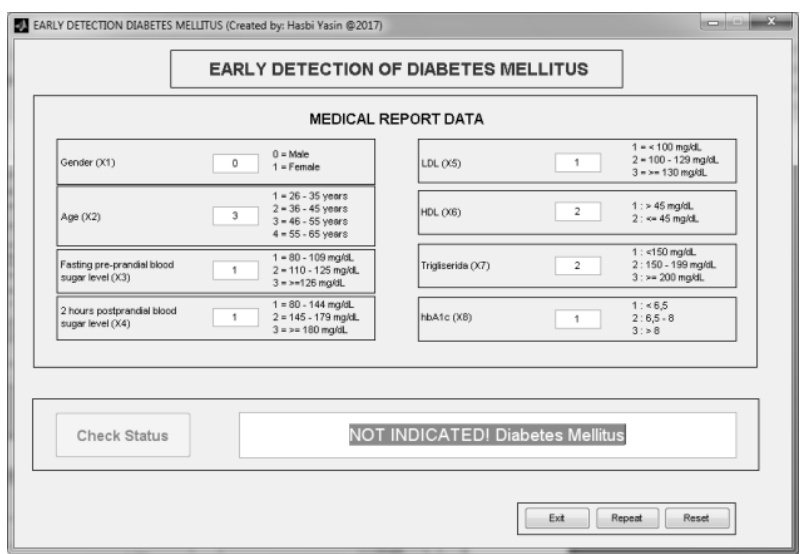

Fig 3. Example 1 for Diabetes Mellitus Early Detection Application

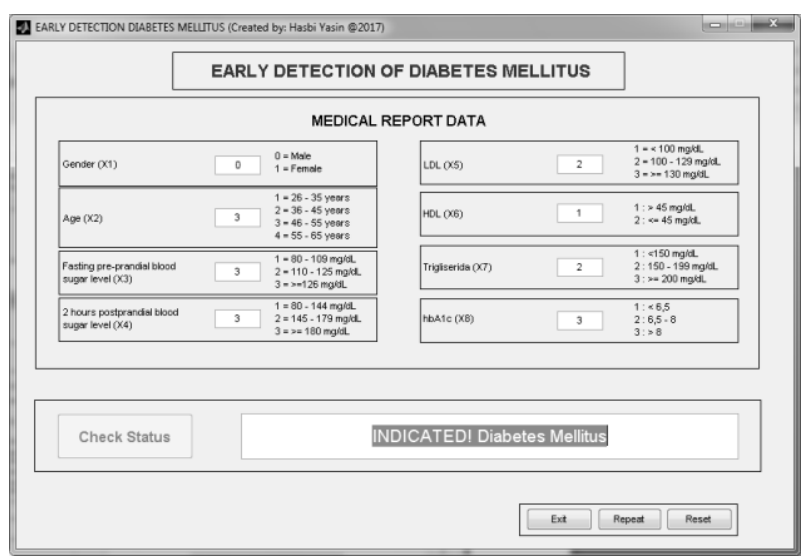

Fig 4. Example 2 for Diabetes Mellitus Early Detection Application

To repeat with the same data input, press the "Repeat" button. To change all data inputs, press the "Reset" button. After finishing, press "Exit" button. 


\section{Conclusion}

The estimation of a model for classifying the contract of Diabetes Mellitus uses FFNN model with binary sigmoid activation function. GUI application applied can be used for detecting the contract of Diabetes Mellitus with an accuracy level of $92.44 \%$. This GUI can be used as an early warning diabetes mellitus in medical report.

\section{References}

[1] B. Pardamean, A. Budiarto, and R. E. Caraka, Bioinformatika dengan R Tingkat Lanjut, 1st ed. Yogyakarta: Teknosains, 2018

[2] F. Chandra and T. Restuastuti Bagian Ilmu kesehatan Masyarakat Kedokteran Komunitas Fakultas Kedokteran Universitas Riau, "Faktor-Faktor Risiko Pasien Diabetes Melitus," Ber. Kedokt. Masy., vol. 23, no. 3, pp. 142-147, 2007.

[3] Jamilatuzzahro, R. . Caraka, and R. Herliansyah, Aplikasi Generalized Linear Model dengan R, 1st ed. Yogyakarta: INNOSAIN Graha Ilmu Yogyakarta, 2018.

[4] a C. Atkinson, "Regression diagnostics," Encycl. Stat. Sci., vol. 7, pp. 689-694, 1986.

[5] C. Chang and C. Lin, "LIBSVM : A Library for Support Vector Machines," ACM Trans. Intell. Syst. Technol., vol. 2, pp. 1-39, 2013.

[6] H. Yasin, R. E. Caraka, Tarno, and A. Hoyyi, "Prediction of crude oil prices using support vector regression (SVR) with grid search - Cross validation algorithm," Glob. J. Pure Appl. Math., vol. 12, no. 4, 2016.

[7] R. E. Caraka and S. A. Bakar, "Evaluation Performance of Hybrid Localized Multi Kernel SVR (LMKSVR) In Electrical Load Data Using 4 Different Optimizations," J. Eng. Appl. Sci., vol. 13 , no. 8, 2018.

[8] R. E. Caraka, S. A. Bakar, B. Pardamean, and A. Budiarto, "Hybrid Support Vector Regression In Electric Power Load During National Holiday Season," in Innovative and Creative Information Technology (ICITech), 2017, pp. 1-6.

[9] M. T. Hagan, H. B. Demuth, and M. H. Beale, "Neural Network Design," Bost. Massachusetts PWS, vol. 2, p. 734, 1995.

[10] D. Svozil, V. Kvasnička, and J. Pospíchal, "Introduction to multi-layer feed-forward neural networks," in Chemometrics and Intelligent Laboratory Systems, 1997, vol. 39, no. 1, pp. 4362.

[11] B. Warsito, Kapita Selekta Statistika Neural Network, 1st ed. Semarang: BP Undip, 2009.

[12] Haykin, Neural Networks and Learning Machines, vol. 3, no. v. 10. 2009.

[13] S. Kusumadewi, "Aplikasi Informatika Medis untuk Penatalaksanaan Diabetes Melitus Secara Terpadu,” Semin. Nas. Apl. Teknol. Inf., vol. 2009, no. Snati, p. C-22-C-27, 2009.

[14] L. W. Pandjaitan, Dasar-Dasar Komputasi Cerdas. Yogyakarta: Andi, 2007.

[15] L. V. Fausett, Fundamental of Neural Network: Architecture, Algorithm and Application. 1994.

[16] R. E. Caraka, "Prediction of Euro 50 Using Back Propagation Neural Network (BPNN) and Genetic Algorithm (GA)," Int. J. Eng. Bus. Manag., vol. 1, no. 1, pp. 35-42, 2017.

[17] American Diabetes Association, "Diagnosis and classification of diabetes mellitus," Diabetes Care, vol. 32, no. SUPPL. 1, pp. S62-S67, 2009. 